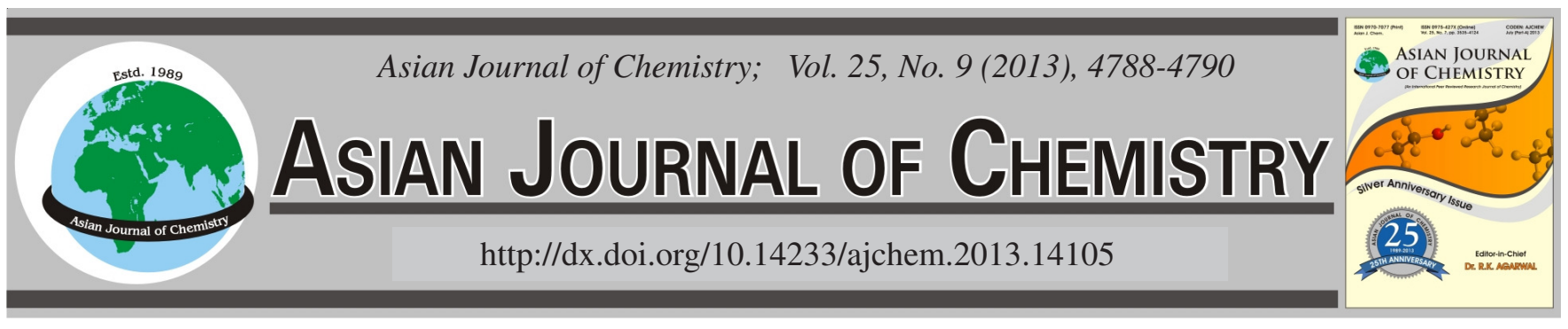

\title{
Validated RP-HPLC Method for the Determination of Mycophenolate Mofetil in Tablet Dosage Forms
}

T. Vijaya Bhaskara Reddy, G. Ramu, M. SRavan Kumar and C. Rambabu*

Department of Chemistry, Acharya Nagarjuna University, Nagarjuananagar-522 510, India

*Corresponding author: E-mail: rbchintala@gmail.com

\begin{abstract}
A precise, accurate and more sensitive RP-HPLC method is developed to estimate the amount of mycophenolate mofetil in pure and tablets using Waters-Alliance HPLC system equipped with auto sampler and ultra-violet detector. The method is carried out on a Symmetry $\mathrm{C}_{18}(4.6 \mathrm{~mm}$ ID $\times 150 \mathrm{~mm}, 5 \mu \mathrm{m}$, Make: XTerra) with a mobile phase consisting of acetonitrile and potassium dihydrogen phosphate buffer of $\mathrm{pH}=4.0$ in the ratio $65: 35$ volume/volume at a flow rate of $0.7 \mathrm{~mL} / \mathrm{min}$. The detection of eluted components is carried out at a wavelength of $216 \mathrm{~nm}$. The retention time of mycophenolate mofetil is found to be $2.647 \mathrm{~min}$. The developed method is validated in terms of accuracy, precision, linearity, limit of detection, limit of quantization. The linearity limits, LOD and LOQ of the developed method are found to be 10-50, 0.052 and $0.171 \mu \mathrm{g} \mathrm{mL} \mathrm{L}^{-1}$, respectively. The developed method is found to be simple, fast and economic and hence it can be used as an alternative method in quality control.
\end{abstract}

Key Words: RP-HPLC, Mycophenolate mofetil, Retention time, Linearity, Quality control.

\section{INTRODUCTION}

Mycophenolate mofetil (MMF) is an immunosuppressant and prodrug of mycophenolic acid, used extensively in transplant medicine. It is a reversible inhibitor of inosine monophosphate dehydrogenase ${ }^{1}$ (IMPDH) in purine biosynthesis, more specifically guanine synthesis, which is necessary for the growth of T cells and B cells. Mycophenolate mofetil is also used in the treatment of autoimmune diseases, such as Behcet's disease, pemphigus vulgaris and systemic lupus erythematosus. The chemical name for mycophenolate mofetil is 2-morpholinoethyl (E)-6-(1,3-dihydro-4-hydroxy-6methoxy-7-methyl-3-oxo-5-isobenzofuranyl)-4-methyl-4hexenoate. Its empirical formula is $\mathrm{C}_{23} \mathrm{H}_{31} \mathrm{NO}_{7}$ with molecular weight 433.50 and soluble in acidic medium. It is available in the brand names such as CellCept, Myfortic.

One UV-spectrophotometric method is reported ${ }^{2}$ to estimate mycophenolate mofetil in bulk and pharmaceutical formulations at $250 \mathrm{~nm}$ in $0.1 \mathrm{~N}$ hydrochloric acid $(\mathrm{pH} 1.2)$ using acetate buffer ( $\mathrm{pH} 4.5$ ). A high-performance liquidchromatography method ${ }^{3}$ is developed and validated for the estimation of mycophenolate mofetil in tablets, capsules and nanoparticles by using photo diode array detector. A simultaneous determination of mycophenolic acid and valproic acid in human plasma by HPLC ${ }^{4}$ is reported based on derivatization by high-performance liquid chromatography with fluorescence detection. A few LC-MS/MS ${ }^{5-10}$ methods have been reported for the determination of mycophenolate mofetil present in biological fluids in humans. A few HPLC ${ }^{11-14}$ are also reported in the literature to determine the amount of the drug mostly in biological matrixes. Most of the reported methods are concentrated on the biological fluids. From the extensive surrey of the literature it is found that a very few methods are present to determine the drug in formulations. Therefore the author has attempted to develop a more sensitive HPLC method for the assay of the chosen drug in pharmaceutical formulations. The LOD and LOQ values of the reported method are very much lower than that of that of the reported $\operatorname{method}_{3}$. More over the linearity limits for the proposed method are 10-50 $\mu \mathrm{g}$ $\mathrm{mL}^{-1}$ which is lower than the existing method of $120-800 \mu \mathrm{g}$ $\mathrm{mL}^{-1}$ indicating that the method is more sensitive. The UV absorption spectrum (Fig. 1) of the drug gives three peaks at 216, 250 and $304 \mathrm{~nm}$. It is found that the absorbance at 216 $\mathrm{nm}$ is nearly five times more than the one at $250 \mathrm{~nm}$. Hence the all spectral measurements are made at $216 \mathrm{~nm}$ to achieve better sensitivity.

\section{EXPERIMENTAL}

The separation is carried out on Waters-Alliance HPLC system equipped with auto sampler, binary gradient pump, dual wavelength $\mathrm{UV}$-visible detector and symmetry $\mathrm{C}_{18}(4.6$ 


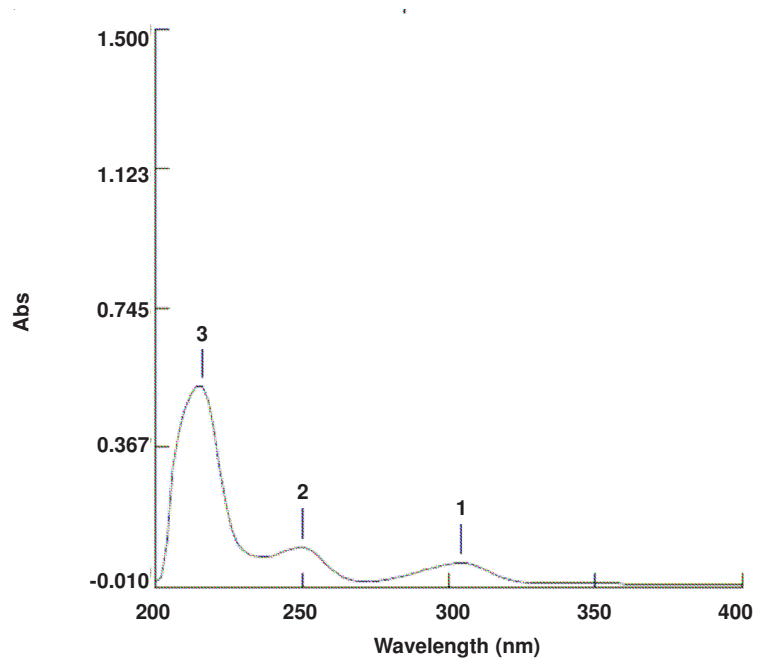

Fig. 1. UV Absorption spectrum of the mycophenolate mofetil

$\mathrm{mm}$ ID $\times 150 \mathrm{~mm}, 5 \mu \mathrm{m}$, Make: XTerra) column. Empower chromatography data software is used to get the reports.

Analytical grade potassium dihydrogen phosphate and ortho phosphoric acid are purchased from Qualigens Fine Chemicals Ltd., Mumbai. Acetonitrile of HPLC grade is obtained from E. Merck. (India) Ltd., Mumbai. Mycophenolate mofetil of highest purity (99.8 \%) is gifted by Dr. Reddy's Laboratories Ltd., Hyderabad. The commercially available mycophenolate mofetil tablets CellCept and Myfortic are purchased from the local market.

Preparation of mobile phase: The mobile phase is prepared by adding of $650 \mathrm{~mL}$ acetonitrile (HPLC grade) to $350 \mathrm{~mL}$ of $0.7 \%$ potassium dihydrogen phosphate buffer of $\mathrm{pH} 4.0$ (the $\mathrm{pH}$ of the solution is adjusted to 4.0 by adding $1 \%$ ortho phosphoric acid solution), sonicated and filtered through $0.45 \mu$ membrane filter before use.

Preparation of the mycophenolate standard and sample solution: Stock solution of the mycophenolate mofetil is prepared by dissolving accurately weighed $10 \mathrm{mg}$ of mycophenolate standard (for preparation of test solution, weight of the sample powder equivalent to $10 \mathrm{mg}$ of the mycophenolate is taken) in $7 \mathrm{~mL}$ of mobile phase in a $10 \mathrm{~mL}$ volumetric flask, sonicated, made up to the mark with the mobile phase and filtered through $0.45 \mu \mathrm{m}$ membrane filter. A series dilute solutions ranging from $10-50 \mu \mathrm{g} \mathrm{mL}^{-1}$ are prepared from the stock solution in mobile phase.

Chromatographic conditions: The mobile phase is pumped from the solvent reservoir into the column at a flow rate of $0.7 \mathrm{~mL} / \mathrm{min}$. The column is allowed to equilibrate for $0.5 \mathrm{~h}$ prior to the injection of $20 \mu \mathrm{L}$ the standard. The detection of the components that are present in the elutent is monitored at $216 \mathrm{~nm}$. The working standard solution of concentration 30 $\mu \mathrm{g} \mathrm{mL} \mathrm{m}^{-1}$ is injected into $20 \mu \mathrm{L}$ loop and the chromatogram is recorded and represented in Fig. 2. The retention time of the drug is found to be $2.647 \mathrm{~min}$. The system suitable parameters such as tailing factor and number of theoretical plates are found to be within the limits and are reported in Table-1.

Precision: The intra-day precision (concordance of the experimentally determined values) of a method is expressed in terms of statistical parameters such as standard deviation and RSD \%. The RSD \% is calculated from the standard deviation

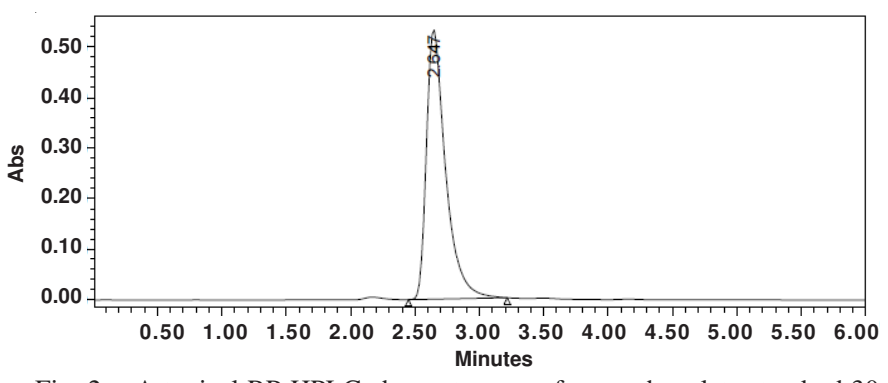

Fig. 2. A typical RP-HPLC chromatogram of mycophenolate standard 30 $\mu \mathrm{g} \mathrm{mL} \mathrm{m}^{-1}$

\begin{tabular}{|c|c|c|c|}
\hline \multicolumn{4}{|c|}{$\begin{array}{l}\text { TABLE-1 } \\
\text { SYSTEM SUITABILITY PARAMETERS }\end{array}$} \\
\hline Conc. & Parameters & Obtained value & Acceptance value \\
\hline \multirow{2}{*}{$\begin{array}{l}30 \mu \mathrm{g} \\
\mathrm{mL}^{-1}\end{array}$} & Tailing factor & 1.6 & Not more than 2.0 \\
\hline & $\begin{array}{l}\text { Theoretical plate } \\
\text { count }\end{array}$ & 2639 & $\begin{array}{c}\text { Not less than } \\
2000\end{array}$ \\
\hline
\end{tabular}

and mean area of five replicate measurements of the working standard solution of concentration $30 \mu \mathrm{g} \mathrm{mL}^{-1}$. Inter-day precision of the method is determined by carrying out the experiment on different days using same instrument and same column under similar chromatographic conditions. The RSD \% value for the five replicate measurements is found to be 0.29 (Table-2).

TABLE-2

PRECISION OF THE METHOD

\begin{tabular}{lclc}
\hline \multicolumn{2}{c}{ Intra-day precision } & \multicolumn{2}{c}{ Inter day precision } \\
\hline Injection & Area & Injection & Area \\
\hline Injection-1 & 4991365 & Injection-1 & 4860869 \\
Injection-2 & 4963809 & Injection-2 & 4828763 \\
Injection-3 & 5000570 & Injection-3 & 4843661 \\
Injection-4 & 4817340 & Injection-4 & 4854142 \\
Injection-5 & 4820237 & Injection-5 & 4862617 \\
Average & 4918664 & Average & 4850011 \\
Standard deviation & 92177.1 & Standard deviation & 14015.1 \\
RSD (\%) & 1.87 & RSD (\%) & 0.29 \\
\hline
\end{tabular}

Accuracy: The accuracy (closeness of the experimentally determined value to the most probable value or true value) of the method is determined by recovery experiments. The recovery studies are carried out at three different concentrations i.e., 50,100 and $150 \%$ of target concentration and presented in Table-3.

\begin{tabular}{cccccc}
\multicolumn{7}{c}{ TABLE-3 } \\
ACCURACY OF THE PROPOSED METHOD \\
\hline $\begin{array}{c}\text { Conc } \\
(\%)\end{array}$ & Area & $\begin{array}{c}\text { Amount } \\
\text { added }\end{array}$ & $\begin{array}{c}\text { Amount } \\
\text { found }\end{array}$ & $\begin{array}{c}\text { Recovery } \\
(\%)\end{array}$ & $\begin{array}{c}\text { Mean } \\
\text { recovery }\end{array}$ \\
\hline 50 & 2908918 & $5.23 \mathrm{mg}$ & $5.31 \mathrm{mg}$ & 101.5 & \\
100 & 5310069 & $9.8 \mathrm{mg}$ & $9.69 \mathrm{mg}$ & 99.9 & $99.9 \%$ \\
150 & 7387647 & $13.6 \mathrm{mg}$ & $13.4 \mathrm{mg}$ & 99.1 & \\
\hline
\end{tabular}

Acceptance criteria: The per cent of recovery for each level should be between 98.0-102.0\%.

Linearity: A series of standard solutions (10-50 $\left.\mu \mathrm{g} \mathrm{mL}^{-1}\right)$ are injected into the $20 \mu \mathrm{L}$ loop and the chromatogram is recorded for each concentration. The calibration curve is constructed by plotting concentration against peak area and is represented in Fig. 3. The correlation between concentration of the drug and peak area is expressed in terms of correlation 


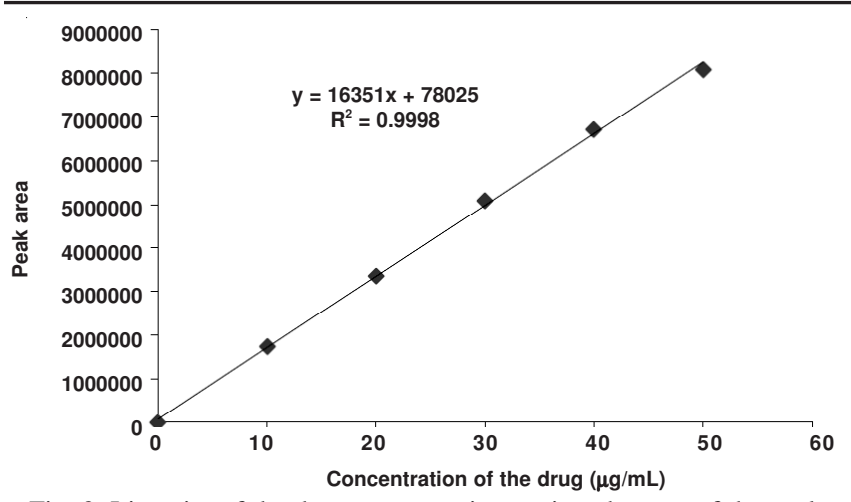

Fig. 3. Linearity of the drug concentration against the area of the peak

coefficient. The slope and intercept are evaluated by linear regression analysis using linear least square method. The slope, intercept and correlation coefficient values are given in Table- 4 .

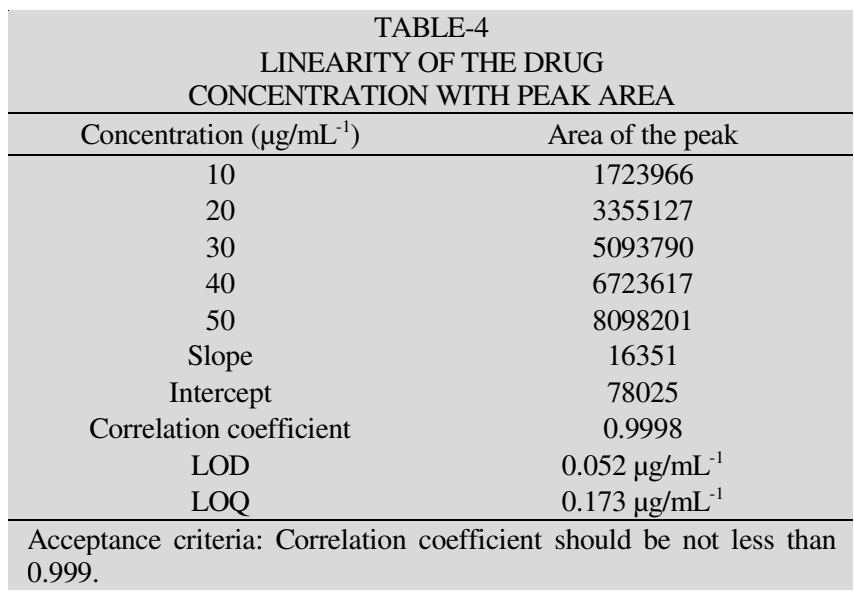

Limit of detection (LOD) and limit of quantification (LOQ): The limit of detection (LOD) is the smallest concentration of the analyte that gives the measurable response. The limit of quantification (LOQ) is the smallest concentration of the analyte, which gives response that can be accurately quantified. The experimentally determined values of LOD and LOQ are given in Table-4. LOD and LOQ are calculated using (3.3 $\times$ standard deviation)/slope of calibration curve and $(10.0 \times$ standard deviation)/slope of calibration curve, respectively. The LOD and LOQ of the solution are found to be 0.0521 and $0.171 \mu \mathrm{g} \mathrm{mL}^{-1}$.

Robustness: Robustness of the proposed method is checked by making slight deliberate change in the experimental procedures. In the present method a deliberate change in the flow rate and mobile phase composition is made to evaluate the impact on the method. (Table-5).

\section{TABLE-5}

STUDY OF ROBUSTNESS OF THE PROPOSED METHOD

\begin{tabular}{cccccc}
\hline $\begin{array}{c}\text { Flow rate } \\
(\mathrm{mL} / \mathrm{min})\end{array}$ & $\begin{array}{c}\text { Plate } \\
\text { count }\end{array}$ & $\begin{array}{c}\text { Tailing } \\
\text { factor }\end{array}$ & $\begin{array}{c}\text { Mobile } \\
\text { phase } \\
\text { composition }\end{array}$ & $\begin{array}{c}\text { Plate } \\
\text { count }\end{array}$ & $\begin{array}{c}\text { Tailing } \\
\text { factor }\end{array}$ \\
\hline $0.6 \mathrm{~mL} / \mathrm{min}$ & 2444.1 & 1.7 & $10 \%$ less & 2557.3 & 1.2 \\
$0.7 \mathrm{~mL} / \mathrm{min}$ & 2639.8 & 1.6 & Actual & 2639.8 & 1.6 \\
$0.8 \mathrm{~mL} / \mathrm{min}$ & 2648.9 & 1.5 & $10 \%$ high & 2503.7 & 1.6 \\
\hline
\end{tabular}

*Results for actual flow $(0.7 \mathrm{~mL} / \mathrm{min})$ have been considered from assay standard. *Results for actual mobile phase composition $(65: 35$ acetonitrile:buffer) have been considered.

\section{RESULTS AND DISCUSSION}

UV absorption spectrum of mycophenolate is scanned from 200-400 nm with $2 \mathrm{~nm}$ band width which indicates three peaks at 216, 250 and $304 \mathrm{~nm}$ (Fig. 1). It is found that the absorbance at $216 \mathrm{~nm}$ is nearly five times more and hence we have selected $216 \mathrm{~nm}$ as the suitable wavelength for recording chromatograms in the proposed RP-HPLC method. The mixture of potassium dihydrogen phosphate solution and acetonitrile (35:65) is selected as mobile phase with a flow rate $0.7 \mathrm{~mL} /$ $\mathrm{min}$. The retention time is found to be $2.647 \mathrm{~min}$. The drug obeys linearity in the range of $10-50 \mu \mathrm{g} \mathrm{mL}^{-1}$ and the correlation coefficient is found to be 0.9999 . The developed method is found to be accurate and precise as indicated by recovery studies and RSD \% not more than 2.0. Moreover LOD and LOQ are found to be less than the reported values. Recovery studies are performed at 50,100 and $150 \%$ concentration levels and the results are found to be satisfactory. The results indicate that the proposed method is found to be more sensitive than the existing methods.

\section{Conclusion}

The proposed RP-HPLC method for the estimation of mycophenolate mofetil in dosage forms is found to be more precise and sensitive. The per cent recovery of the drug (accuracy) indicates that the proposed method is selective. The drug is eluted in a reasonable retention time $2.647 \mathrm{~min}$ which indicates speed of the analysis, hence small portions of the solvents are sufficient for the complete analysis therefore the cost of the method is reduced.

\section{ACKNOWLEDGEMENTS}

The authors are thankful to Pharma Train, Hyderabad for providing the laboratory facilities.

\section{REFERENCES}

1. B. Fulton and A. Markham, Drugs, 51, 278 (1996).

2. S. Verma, H. Gupta, O. Alam, P. Mullick, N. Siddiqui and S. Khan, J. Appl. Spectrosc., 76, 876 (2009).

3. Surajpal Verma, Eur. J. Anal. Chem., 5, 156 (2010).

4. Y. Zhong, Z. Jiao and Y. Yunqiu, Biomed. Chromatogr., 20, 319 (2006).

5. J. Kuhn, C. Gotting and K. Kleesiek, Talanta, 80, 1894 (2010).

6. J. Kuhn, C. Prante, K. Kleesiek and C. Gotting, Clin. Biochem., 42, 83 (2009).

7. B. Shen, S. Li, Y. Zhang, X. Yuan, Y. Fan, Z. Liu, Q. Hu and C. Yu, J. Pharm. Biomed. Anal., 50, 515 (2009).

8. M.-O. Benoit-Biancamano, P. Caron, E. Levesque, R. Delage, F. Couture and C. Guillemette, J. Chromatogr. B, 858, 159 (2007).

9. H. Benech, S. Hascoe, V. Furlan, A. Pruvost and A. Durrbach, J. Chromatogr. $B, \mathbf{8 5 3}, 168$ (2007).

10. M. Platzer, K. Jahn, J. Wohlrab and R.H.H. Neubert, J. Chromatogr. B, 755, 355 (2001).

11. V. Srivatsan, A.K. Dasgupta, P. Kale, R. Verma, P. Joshi, D. Soni, M. Patel, G. Soni, J. Patel and H. Modi, J. Chromatogr. A, 1031, 259 (2004).

12. D. Teshima, N. Kitagawa, K. Otsubo, K. Makino, Y. Itoh and R. Oishi, J. Chromatogr. B, 780, 21 (2002).

13. U.D. Renner, C. Thiede, M. Bornhauser, G. Ehninge and H.-M. Thiede, Anal. Chem., 73, 41 (2001).

14. K. Na-Bangchang, O. Supasyndh, T. Supaporn, V. Banmairuroi and J. Karbwang, J. Chromatogr. B, 738, 169 (2000). 